\title{
DE CAÍN Y DE METRALLA
}

\section{Esther Acevedo}

Pequeño en dimensiones, de tonos agradables, el cuadro de Fernando Best Pontones sobre La Decena Trágica, firmado y autografiado en 1913, es parte de la "otra" lectura de los hechos, es decir, de la lectura que se pudo hacer desde el flanco de quienes acabaron con el breve verano maderista a la mañana siguiente de su triunfo. Best tenía 24 años cuando pintó su cuadro y comenzaba una carrera que se desarrollaría en la década de la lucha revolucionaria.

Una lectura de los diferentes planos del cuadro descubre el posible mensaje que Best quería transmitir a quien sería el dueño del cuadro: Félix Díaz. El fondo lo ocupa la añeja construcción de la Ciudadela-que en aquel momento exa un depósito de armas y municiones-, centro de una zona poblada y a poca distancia "de un barrio residencial que alojaba entre otros extranjeros a los funcionarios y empleados de la embajada norteamericana" . Félix Diaz tomó la Ciudadela el 9 de febrero de 1913, después del breve combate en el Zócalo que le costó la vida al más prestigiado y añoso de los militares insurrectos, el general Bernardo Reyes. Las fuerzas leales retuvieron Palacio Nacional y los insur rectos, con Félix Díaz al frente, se replegaron hacia la Ciudadela. El segundo plano del cuadro remite a una ubicación más precisa: el lado norte del predio, donde resguardados tras una verja se ven cuatro soldados de uniforme gris, un oficial vestido de azul y un cañón. Un poste de luz derribado y la visible calma en la actitud de estos cinco personajes parecen indicar que ya han pasado algunos días de combate. Uno de los soldados se encuentra en posición de vigía, mientras los dos encargados del poderoso cañón "Chamond-Mondragón" están más bien a la expectativa que en guardia. El oficial, protegido tras la barda, sostiene una hoja en la mano y habla con un subalterno.

La crónica de los sucesos en la prensa tomó partido. La felicista o felixista como ellos la nombraban relata que

El domingo 9 de febrero de 1913 despertó la ciudad sobresaltada. Las personas que se levantan al alba notaron extraña agitación en las calles. Gentes apresuradas

\footnotetext{
${ }^{1}$ Héctor Aguilar Camín, La frontera nómada Sonora y la Revolución Mexicana, México, Siglo XXI, 1981, p. 270
} 
corrían apresuradas Corrillos en que se hablaba acaloradamente. Las tiendas, los estanquillos, los pequeños establecimientos que a esa temprana hora parecen hormigueros humanos, se hallaban cerrados y en las esquinas no se veia un solo gendarme No tardó en correr por toda la ciudad con rapidez de relámpago una noticia tan estupenda como inesperada: iLa guarnición se había sublevado contra el Presidente Madero! A pesar del peligro que en esos casos corre la población pacífica, el vecindario se echó a la calle en busca de nuevas y empezó a darse cuenta de lo que hasta esos instantes había ocurrido, recogiendo aquí un detalle, más allá del rumor, observando con sus propios ojos el lugar en que se registró la parte principal de los acontecimientos con que se inició la tremenda semana roja de la Capital que acabó con un régimen político apenas creado. ${ }^{2}$

Durante la tregua del día 10 un reporter del The Mexican Herald entrevistó al General Díaz, quien lamentó

La muerte del Gral Reyes y la sangre que se ha derramado. El movimiento fue organizado para llevar a cabo, sin grandes trastornos, el cambio de la situación política del país, mediante la renuncia inevitable del Sr. Madero y su Gabinete; pero la conducta de los jefes y oficiales a que me refiero dio un giro inesperado a los acontecimientos que no podría decir cómo se resolverá ${ }^{3}$

Uno de los estudios históricos del suceso publicado recientemente, explica que

Una vez concentrada la mayor parte de las tropas leales, el general Huerta ordenó el día 11 un ataque de caballería sobre la Ciudadela. El resultado fue un rotundo fracaso y una matanza tremenda, pues las tropas rurales en su mayor parte fueron acribilladas por el fuego de fusilería y ametralladoras de los rebeldes. En la tarde se intentó un nuevo ataque con resultados similares; las bajas fueron de cuatrocientos hombres aproximadamente. El día 12 se llevaron a cabo tiroteos y fuego de artillería ocasionando graves daños a la población civil. $^{4}$

Nada de esto queda descrito en el armonioso cuadro. Los combates más intensos fueron el día 14 de febrero. "Los fuegos de infantería y artillería se iniciaron al amanecer", sigue Luis Garfias, "incrementando su intensidad

${ }^{2} \mathrm{~J}$ Rodríguez (ed), La decena trágica en México Datos veridicos tomados en el mismo teatro de las sucesos por un escritor metropolitano, México, ediciones El Obrero, León, Guanajuato, p 21.

${ }^{3}$ Ibid., p. 25

${ }^{4}$ Luis Garfias, "Aspectos militares de la Decena Trágica", Madero y el tiempo nuevo. Así fue la Revolución Mexicana, vol. 3, 1985, p. 451. 
hacia el mediodía. El 15 prosiguió el duelo de las artillerías; los sitiados sacaron la mejor parte pues contaban con diez y seis piezas de artillería y un mayor número de granadas, mientras los gobiernistas poseían tan sólo once piezas y una reducida cantidad de granadas rompedoras. " ${ }^{5}$ Los días 16 y 17 se emplearon en discutir cómo se llevaría a cabo el ataque. "Para el 18 Huerta ya había entablado tratos y negociaciones con los generales Mondragón y Díaz decidiendo traicionar al gobierno establecido." 6

El Pacto de la Ciudadela o de la Embajada comprometía al general Victoriano Huerta a "ocupar la presidencia provisional, (a) que su gabinete fuera nombrado por Félix Díaż y que éste recibiría el apoyo de Huerta para postularse a la presidencia definitiva en las próximas elecciones que debían convocarse cuanto antes." "7

El momento que el cuadro representa se aclara completamente a través de la prensa. La Revista Universal de abril de 1913 lo publicó en sus páginas junto con otras obras de Best. ${ }^{8}$ La obra se titula Ciudadela, 13 de febrero de 1913. También a través de las revistas se accede al modo en que Best realizó su cuadro. Es seguro que con las portadas de La Semana Ilustrada en la mano, en que se destacaron los eventos de la semana, Best compuso esta pintura. Tostado es quien firma los grabados. Técnica que por motivos de reproducción todavía usaban algunas publicaciones que no estaban a la vanguardia de la impresión fotográfica. Fueron las fotografías reproducidas -reproducidas también en otras publicaciones- la verdadera fuente de las portadas de La Semana Ilustrada del 25 y 28 de febrero del mismo año. Su identificación pone en evidencia que Best no fue un testigo ocular de los hechos que describe. La primera de estas portadas se titula "Vigía felicista en la Ciudadela", y corresponde, en la pintura de Best, al primer soldado, en la misma posición, con el mismo uniforme que usaron los cadetes de la Escuela Militar de Aspirantes de Infantería de Tlalpan. La otra por tada permitióa Best detallar perfectamente el tipo de cañón usado, así como el espacio que ocupaba el bosquecillo entre el edificio de la Ciudadela y la verja donde estaban apostados los soldados. El oficial con la nota en la mano acaso fue invención del pintor o proviene de alguna fotografía ignota. El uso de estas fotografías para componer obras pictóricas era una práctica común. La objetividad histórica

\footnotetext{
${ }^{5}$ Ibid, p. 454

${ }^{6}$ Idem

${ }^{7}$ María Angélica Oliver, "Henry Lane Wilson y el Pacto de la Embajada", Madero y el tiempo muevo. Así fue la Revolución Mexicana, vol 3, 1985, pp 460-461.

${ }^{8}$ La Revista Universal, abril de 1913 Se publican tres tricomías de Femando Best: Coro del Convento de San Joaquín, Primicias Primaverales y Ciudadela, 13 de febrero de 1913
} 
del cuadro no depende de su o sus fuentes sino del sentido que Best les otorgó. Las fotografías fueron testigos de un instante y, como tal, fragmento de una realidad. Best, al plasmarlas en un lienzo, las enlaza en una trama; su visión ante la batalla queda sujeta, por un lado, al destinatario del cuadro, Félix Díaz, y por esto no debía molestar. Traición y violencia no podían aparecer. Por otra parte, el artista seguía una manera de hacer; los cuadros debían ser "bonitos" y este cuadro en particular, por sus atributos pictóricos y temáticos, se inscribe en ese filón que sería característico de su pintura.

Fernando Best pintó este cuadro a fines de febrero y circuló, en donde debiera circular, ya fuera entre los artistas o entre los políticos -o bien, entre políticos y artistas-, en el mes de marzo, cuando Félix Díaz todavía aspiraba a la presidencia. El pequeño cuadro fue el homenaje que rindió el pintor al general en ascenso, testimonio de la calma, la tregua, la facilidad del cambio, el inminente triunfo de los rebeldes. Ya Díaz lo había dicho en la entrevista: "no le gustaba el derramamiento de sangre".

El joven pintor, envuelto en la niebla de los hechos, seguía no obstante una tradición porfirista. Fernando Best, como cualquier alumno de la Academia de San Carlos, sabía probablemente del cuadro que Germán Gedovius había pintado para Porfirio Díaz y conocía bien la tradición pictórica dedicada a las batallas decimonónicas.

Durante los años que Porfirio Díaz gobernó el país, la épica que había llevado a los liberales al poder se vio continuamente representada en cuadros que sus amigos, sus subordinados, le regalaban el día de su cumpleaños o en los aniversarios de dichas gestas. Algunos de los pintores que las ejecutaron fueron figuras como Germán Gedovius, Francisco Paula de Mendoza y José Cusachs. Ellos no fueron testigos oculares de las batallas, pero los guió la buena memoria del General que había participado en los eventos y quien las veía colgadas en sus múltiples habitaciones, públicas o privadas. Sabemos que Mendoza viajó a Oaxaca para poder plasmar en gxandes lienzos la atmósfexa correcta del lugar donde se habían desarrollado las batallas de Miahuatlán y La Carbonera. Mendoza pintó en dimensiones monumentales más de dos cuadros con esta temática y varios que tratan La Batalla del 2 de abril. Gedovius, en cambio, sólo pintó un cuadro de tema histórico: el que muestra a Porfirio Díaz en su caballo blanco como prisionero de los franceses en 1865.

Teodoro Dehesa, gobernador de Veracruz, no conforme con la producción de los artistas mexicanos, mandó pintar grandes lienzos -hasta de cerca de treinta metros cuadrados-al pintor barcelonés José Cusachs. ${ }^{9}$ Al español

\footnotetext{
${ }_{9}^{9}$ Periódico Oficial del Estado Libre y Soberano de Veracruz Llave, 10 de mayo de 1903. La noticia fue encontrada por Jaime Cuadriello.
} 
le pagaron veinte mil pesos mexicanos, mientras el avalúo del cuadro de Gedovius hecho por don Francisco M. Álvarez no pasó de tres mil pesos. ${ }^{10}$ La historia de este encargo resulta reveladora de las formas de hacer de la élite gobernante del porfiriato en su época de ascenso. Los cuadros se encargaron expresamente como un regalo para Porfirio Díaz. El Periódico Oficial publicó el contrato y en él se estipulaba que las obras de arte se debían "sujetar en todo a la verdad histórica, para lo cual se le suplicará al Señor Presidente de la República se sirva proporcionar al artista las noticias, datos y apuntes que necesite con el objeto indicado". ${ }^{11}$ Los cuadros se pintaron en Barcelona, donde José Cusachs radicaba y desde donde debía enviar trimestralmente fotografías de los avances al gobernador Dehesa. Para sufragar los gastos de las dos pinturas de Cusachs, Dehesa se dirigió a sus colegas en la República solicitando la cooperación de cada uno de ellos hasta por 1,000 pesos. El gasto estaba justificado "pues el hacer estas obras de arte se hace con el objeto de perpetuar dos jornadas militares de alta significación política en nuestra historia y de hacer esta donación de lienzos al Gobierno Federal a nombre de los gobernadores de los estados para que sean colocados en el Salón de Embajadores". ${ }^{12}$ Esto sucedía en 1901.

En este marco hay que entender el obsequio de Best a Félix Díaz. Sin embargo, por su formato pequeño, la obra difiere de la producción decimonónica mexicana y se inscribe en el género de la pintura histórica que se hizo en Europa a mediados del siglo xxx cuando, cansada de las formas grandilocuentes, la pintura histórica se tornó intimista.

Una vez que La Revista Universal reprodujo este cuadro en el contexto de "La Semana Roja" como parte de la colección Noris, se ignora a donde fue a parar más adelante.

Se sabe, en cambio, que en junio de aquel aciago año Best expuso 80 pinturas al óleo en el Salón del Centro Asturiano. La crítica nos dice que se trataba de paisajes tomados del natural, y un anónimo escritor de $\bar{E} l$ Imparcial lo calificó como un "bosquejo de la escuela nacional". ${ }^{13}$ Las definiciones de lo nacional nunca han sido estáticas; su riqueza -entre otras cosas-reside en descubrir y explicar históricamente la variación del concepto y el rostro pictórico que va tomando.

Firmando con la inicial C, alguien ofreció algunos datos sobre el pintor

\footnotetext{
${ }^{10}$ Elisa García Barragán, Manuel F Álvarez, algunos escritos. Cuadernos de Arquitectura y Conservación del Patrimonio Artístico, p. 148.

${ }^{11}$ Periódico Oficial del Estado Libre y Soberano de Veracruz Llave.

${ }^{12}$ Los cuadros se encuentran hoy en el Museo Nacional de Historia, al igual que algunos de Francisco Paula de Mendoza y el de Germán Gedovius.

${ }^{13}$ El Imparcial, 30 de junio de 1913.
} 
desde la revista Páginas Primaverales. Best estudió en la Escuela Nacional Primaria Superior número 7, su primer maestro de pintura fue Gilberto García y entró a la Academia de San Carlos en calidad de supernumerario; fue discípulo de Antonio Fabrés y tenía su estudio en la calle de Santo Domingo. Para subsistir se dedicó al comercio, decoraba muebles y pintaba puertas para El Palacio de Hierro. Poco después entró en contacto con el fotógrafo Noris, para quien pintaba los trajes de las amplificaciones que aquél realizaba.

En el ámbito de lo artístico, el año de 1913 implicó cambios propicios para Best y para los estudiantes de la Escuela Nacional de Bellas Artes. Nemesio García Naranjo, Ministro de Instrucción Pública y Bellas Artes en el gabinete de Victoriano Huerta, nombró, en agosto, a Alfredo Ramos Martínez, director de la Escuela Nacional de Bellas Artes. Este último no estaba muy lejos de los gustos y preferencias de Fernando Best. Ramos Martínez impulsó la creación de la Escuela de Barbizon de Santa Anita como un centro para el fomento de un arte naturalista, revelador de los valores que a su entender eran los "nacionales" y que, con el tiempo y en otro momento, abrirían nuevos modos de hacer.

Las divisiones que las academias decimonónicas habían impuesto a los artistas se disolvían hacia el comienzo del siglo y los pintores podían dedicarse simultáneamente a varios géneros. Sin embargo, ciertos alumnos tomaron el paisaje como especialidad. Gilberto Chávez, Armando García Núñezy el propio Best son algunos de ellos. Estos tres abordaron el paisaje con una técnica pictórica distinta a la del maestro decimonónico del paisaje José Ma. Velasco. La adopción de una pincelada gruesa y rápida les permitió crear una "impresión" captando lo instantáneo de los eventos a través de las vibraciones de luz y color que se plasmaban en el lienzo.

$\mathrm{El}$ año de 1914 no se fue sin grandes cambios políticos. Derrotado Victoriano Huerta, Gerardo Murillo, el artista que más había apoyado a Carranza, fue nombrado Director de la Escuela Nacional de Bellas Artes. Como director, el Dr. Atl ofrecería otros derroteros a la producción artística que los planteados por Alfredo Ramos Martínez. Este último se aislaría en su estudio de Madero produciendo una serie de retratos de la sociedad que aún vivía en la ciudad de México y para la cual la revolución tenía una significación social contraria a sus intereses.

El año de más éxito para Fernando Best fue el de 1916. La exposición de abril en la calle de Madero núm. 28 significó en verdad un hito en la historia del joven pintor. En Revista de Revistas aparece la foto del artista y las obras que expuso. La pequeña nota anunciaba la apertura de la exposición en la calle de Madero, considerada en aquel entonces por José Juan Tablada como 
DOI: http://dx.doi.org/10.22201/iie.18703062e.1993.64.1672

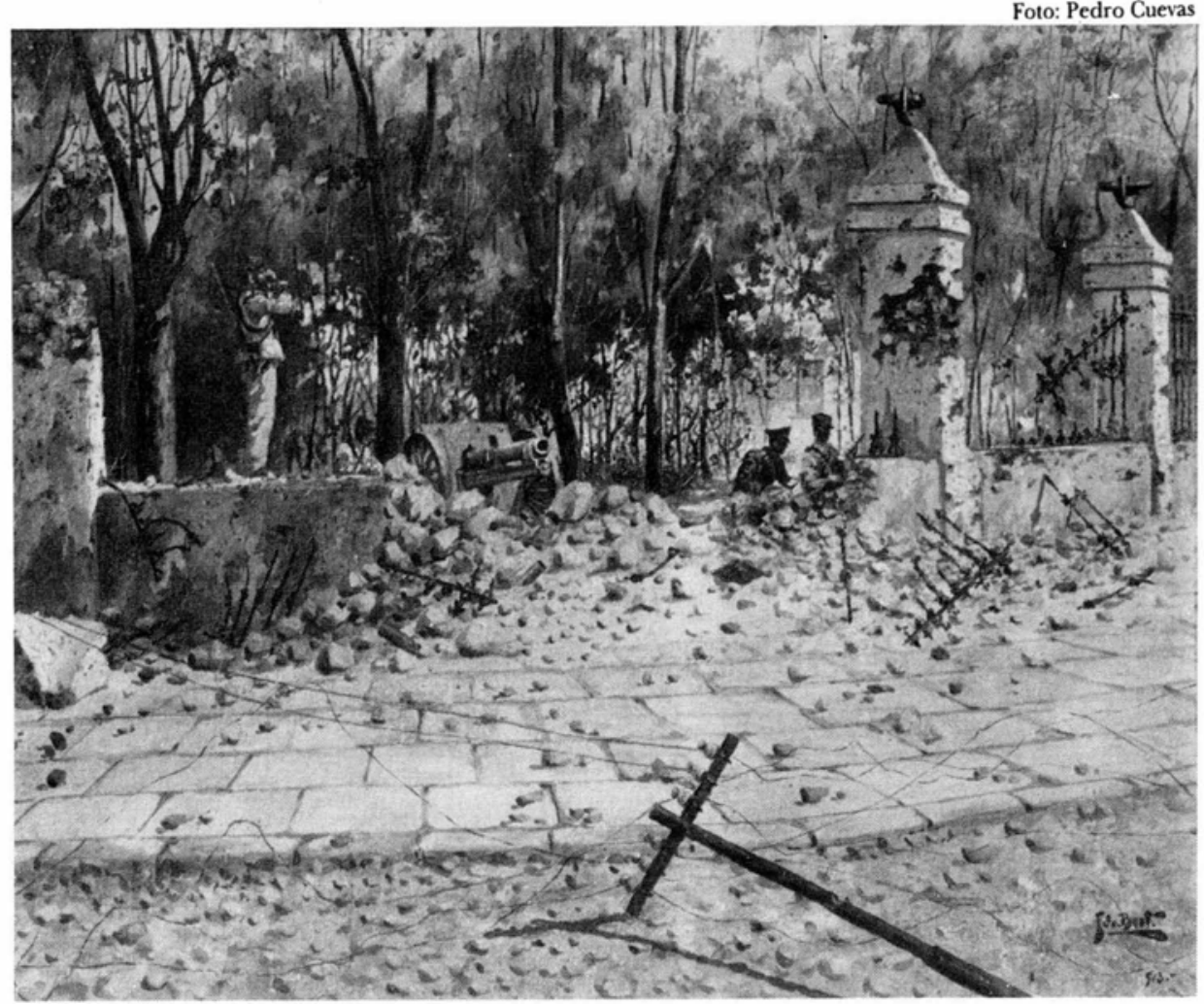

1. Fernando Best Pontones, La decena trágica, 1913. 
"el boulevard no sólo social sino cultural", y por López Velarde como "el caudal único... pulso único de la ciudad". ${ }^{14}$

Fernando Best guardó cuidadosamente en un álbum con cubier tas de piel y grabado con letras doradas: Exposición de MCMXVI, los recortes de periódico, la lișta de las 73 obras con precios y compradores, algunas fotos, una caricatura de Eslo, los 2,274 autógrafos que los visitantes le dejaron a lo largo del mes de abril y las piezas musicales que sus amigos le compusieron.

El acto de clausura de esta memorable exposición se sujetó a un programa literario-musical a cargo de Arnulfo Miramontes, con tres piezas originales. Samuel Bandera y el Dr. Luis Alonso Berganza (su futuro suegro) declamaron algunas poesías, y su amigo Guillermo Luzuriaga fue maestro de ceremonias. Al evento asistió Félix Palavicini, Subsecretario Encargado del Despacho de Instrucción Pública y Bellas Artes ${ }^{15}$ A decir de José Clemente Orozco, en ese momento el Dr "Atl sostenía un enconado duelo político con el ingeniero Palavicini. Parecería que las divisiones sobre los derroteros artísticos subsecuentes se encontraban a discusión.

Fernando Best debió sentirse muy satisfecho pues se vendieron 57 de las 73 obras expuestas en la fabulosa suma de 19,950 pesos. ${ }^{16}$ Sus principales compradores fueron extranjeros: Erik Ostlund compró nueve cuadros en 3,252 pesos y le dejó, en sueco, un mensaje en su libro de autógrafos. Ernesto Woog adquirió seis cuadros en 2,100 pesos y un señor Navarro adquirió cinco cuadros en 1,950 pesos. ¿Se tratará de Francisco Navarro, en cuyo "local" se haría la exposición de septiembre? El cuadro más caro, Patio del Curato de Tacubaya, lo adquirió E.C. Hemmer por 800 pesos.

Parte de la crítica expresó su beneplácito. Bajo un pseudónimo, Verax opinó que Best maneja muy bien el paisaje, pero no se preocupa por la figura. Habla específicamente del cuadro La Leyenda del Pino Roto, donde él encuentra "defectos en la figura humana". ${ }^{17}$ Los interiores coloniales, fríos y austeros, gustaban al escritor Zaquef, quien en cambio criticó agriamente la temática tratada en la exposición Estudios de Mujeres en Biblos de José Clemente Orozco, para la cual José Juan Tablada no regateó elogios. La crítica no era homogénea, tomaba perspectivas diferentes. Una a favor dei paisaje, de la naturaleza, de lo "bonito"; otra veía nuevas temáticas y formas.

\footnotetext{
${ }^{14}$ Fausto Ramirez, Crónica de las artes plásticas en los años de López Velarde 1914-1921, mimeo Este valioso estudio me permitió obtener los datos para consultar la hemerografia.

${ }^{15}$ Félix Palavicini le compró Patio Colonial en 350 pesos.

${ }^{16}$ En 1916, alguien podía abrir una cuenta de cheques con 1,000 pesos, comprarse: un tocadiscos en 125, una máquina de escribir en 75, unos zapatos por 7, un sombrero en 11 o dar un enganche para un terreno de 1,000 metros en Tlalpan con sólo 19.23 pesos. El salario mínimo diario era de un peso

${ }^{17}$ La Leyenda del Pino Roto fue un tríptico que compró en 500 pesos Octavio Campero.
} 
El público que asistió a la exposición también debió ser motivo de agrado para Best, pues no sólo estuvo allí Palavicini sino que desfilaron escultores y pintores de nuevo cuño como Germán Cueto, Alfaro Siqueiros y el mismo Orozco; poetas como Carlos Pellicer; críticos como Vera Córdoba; amigos paisajistas como Armando García Núñez, Guillermo Garduño, Luis Magos; y pintores como Antonio Esnaurrizar y José Escudero y Espronceda quienes se dedicaban mayoritariamente al retrato histórico. Al parecer todo mundo departía.

Al día siguiente de clausurada la exposición -19 de abril de 1916-, Best le escribió a Adolfo de la Huerta, Oficial Mayor de la Secretaría de Gobernación, una carta en la cual le informaba de su decisión de donar 115 pesos para el Asilo Constitucionalista.

Con el éxito en la mano, Best se dispuso a preparar la siguiente exposición para septiembre de ese año en el "local" de Francisco Navarro, sito en la misma calle de Madero, pero ahora en el número 45. La exposición reunió 43 cuadros y no existe información detallada de su desarrollo. El 25 de noviembre de 1916, Best contrajo matrimonio con María Luisa Berganzo, de 16 años, siendo uno de los testigos de boda Germán Cueto. La ceremonia tuvo lugar en el número 130 de la calle de Guadalupe.

Alfonso Toro, un crítico en buena medida conservador, no le negaba a Best en 1917 "facultades para llegar a ser un notable pintor: sabe escoger sus asuntos y es casi siempre agradable; pero creemos que (si) sigue pintando bonito para satisfacer el gusto de su grandísima clientela caerá en el amaneramiento, ojalá se propusiera, él que es un gran laborioso, hacer obra para sí y no sólo para fines mercantiles". ${ }^{18}$ Esta observación confirma lo que había quedado claro en la exposición de 1916. Best producía paisajes que eran adquiridos por los coleccionistas - en gran parte extranjeros- que veían lo mexicano en esas suaves imágenes y se negaban a colgar en sus paredes cuadros con otros motivos y temáticas que empezaban a producirse a raíz de la lucha revolucionaria. El artículo de Toro también habla de la gran cantidad de obra producida, pero siempre bonita, agradable, como el pequeño cuadro -ahora conocido como La Decena Trágica - que no debía molestar desde las paredes a su dueño.

En septiembre de 1919, Best volvió a presentar su obra en los bajos de Madero 15. En una nota breve, sin firma, se anunció que la semana anterior se había inaugurado la exposición con un "numeroso público que desfiló ante las obras pictóricas expuestas por el joven artista, la exhibición termi-

\footnotetext{
${ }^{18}$ Alfonso Toro, "El año artístico", Revista de Revistas, 30 de diciembre de 1917. Artículo proporcionado por Fausto Ramírez.
} 
nará el 30 del actual siendo la entrada libre". ${ }^{19}$ Nada se dice del tema, y el único indicador que de nueva cuenta se ofrece es lo numeroso del público que asistió a los bajos de Madero.

En 1920 -abril y diciembre- Best expuso, tanto en Avenida Madero 42, como en la Escuela Nacional de Bellas Artes. La crítica de ese año, con los antecedentes del anterior, ayuda a entender mejor la problemática del pintor, quien contaba ya con 31 años y vivía en la calle de Secreto 26 en San Ángel. La gacetilla de la exposición de abril nos dice que la obra trata de "asuntos nacionales" y nos acerca a una definición de lo que se entiende con esto. Para ellos, producir "cuadros regionales" admirados por "un numeroso público de amateurs" ${ }^{\prime 20}$ era signo de nacional. Sin embargo, el éxito que Best tenía con los compradores no parecía tenerlo con los nuevos críticos. Ya lo había advertido en 1917 Alfonso Toro, cuando le recomendó hacer una pintura más personal y menos complaciente con su numerosa clientela.

En julio de 1920, a propósito de una exposición de Saturnino Herrán, Carlos Mérida planteó lo erróneo que resulta el criterio de lo que "debe ser la pintura nacionalista". Para él, "el poner un charro, un rebozo, una china poblana o una tehuana no era componer un cuadro nacionalista, ni tampoco éste se daba haciendo una copia servil del calendario azteca o de la piedra de los sacrificios". Mérida continúa así: "para hacer arte nacionalista hay que fundir la parte esencial de nuestro arte autóctono con nuestro sentir actual, pero no en su forma exterior, dijéramos teatral, sino en la forma esencial". El crítico argumenta "que el público se contenta con poco, y de ahí el éxito nacional de un número de las tehuanas en la revista Peluquería nacional, donde de tehuanas no había más que un remedo del carácter de las verdaderas tehuanas: a esta misma causa se debe el exito también de las exposiciones comerciales del señor Best, del señor García Núñez y del señor Fernández". ${ }^{21}$ Mérida era contundente en su juicio sobre la obra de Best, como lo sería la crítica posrevolucionaria.

Los tiempos cambian "Lo que había sido para un círculo de críticos, artistas y compradores lo nacional en la segunda década de la centuria, la posrevolución lo redefinia: el arte y el público al que éste estaba dirigido era otro. La revolución, primero, y ahora la posrevolución habían cambiado los modos de ver, de conceptualizar y de orientar en lo futuro la producción artística. El mecenazgo y el mercado eran otros.

\footnotetext{
${ }^{19}$ Revista de Revistas, 21 de septiembre de 1919. Artículo localizado por Fausto Ramírez

${ }^{20}$ Revista de Revistas, 9 de mayo de 1920 Artículo proporcionado por Fausto Ramírez.

${ }^{21}$ Carlos Mérida, "La verdadera significación de la obra de Saturnino Herrán", Universal Ilustrado, 29 de julio de 1920. [Las cursivas son del autor.] Artículo localizado por Fausto Ramírez.
} 
Al reseñar en diciembre de 1920 la Exposición de la Escuela Nacional de Bellas Artes, Mérida calificó como paisajistas "sólidos" a Ramón Alba y a Fernando Leal, y le concedió a Carrillo Gariel un "estimable valor decorativo" "22 A Best ya ni siquiera lo menciona, como tampoco lo hace Alfonso Toro -quien sí se había ocupado positivamente de él.

La década de los veinte sería rica en propuestas sobre los derroteros de la producción artística. El arte público ocupó el lugar preeminente en los modos culturales de la época, marginando doblemente a Fernando Best, quien seguía aún pintando paisajes "bonitos" dirigidos a un público que pensaba que lo mexicano era captar la fugacidad de un hermoso rincón con atmósfera impresionista.

¿A dónde fue a parar el cuadro histórico que le dedicara eljoven Best a Félix Díaz después de la Decena Trágica? Alguien lo guardó, alguien trató de borrar el autógrafo: "Al Sr. Gral. D. Félix Díaz", aunque por las texturas de las pinceladas fue imposible hacerlo del todo, pues éste quedó esgrafiado. Seguramente alguien lo vendió o lo regaló al Senado de la República, en donde ahora se muestra como parte del decorado patriótico en el Salón Juárez como un episodio de La Decena Trágica.

${ }^{22}$ Carlos Mérida, "La exposición anual de la Escuela de Bellas Artes", Universal Ihustrado, 9 de diciembre de 1920. Axtículo localizado por Fausto Ramírez. 